\title{
Mercury exposure, nutritional deficiencies and metabolic disruptions may affect learning in children Renee Dufault*1, Roseanne Schnoll ${ }^{2}$, Walter J Lukiw ${ }^{3}$, Blaise LeBlanc ${ }^{4}$, Charles Cornett ${ }^{5}$, Lyn Patrick ${ }^{6}$, David Wallinga ${ }^{7}$, Steven G Gilbert ${ }^{8}$ and Raquel Crider ${ }^{9}$
}

\begin{abstract}
Address: ${ }^{1}$ United Tribes Technical College, Bismarck, ND, USA, ${ }^{2}$ Department of Health and Nutrition Sciences, Brooklyn College of CUNY, Brooklyn, NY, USA, ${ }^{3}$ Departments of Neuroscience and Ophthalmology, LSU Neuroscience Center. Louisiana State University Health Sciences Center, New Orleans, LA, USA, ${ }^{4}$ Carl Hayden Bee Research Center, Tucson, AZ, USA, ${ }^{5}$ Department of Chemistry and Engineering Physics, University of Wisconsin-Platteville, Platteville, WI, USA, ${ }^{6}$ Contributing Editor, Alternative Medicine Review, Durango, CO, USA, ${ }^{7}$ Institute for Agriculture and Trade Policy, Minneapolis, MN, USA, ${ }^{8}$ Institute of Neurotoxicology and Neurological Disorders, 8232 14th Avenue NE, Seattle, WA, USA and 'Shepherd University, Shepherdstown, WV, USA

Email: Renee Dufault* - rdufault@uttc.edu; Roseanne Schnoll - rschnoll@brooklyn.cuny.edu; Walter J Lukiw - wlukiw@lsuhsc.edu; Blaise LeBlanc - blaise_ll@hotmail.com; Charles Cornett - cornettc@uwplatt.edu; Lyn Patrick - lpatrick@frontier.net; David Wallinga - dwallinga@iatp.org; Steven G Gilbert - sgilbert@innd.org; Raquel Crider - rcrider01@shepherd.edu

* Corresponding author
\end{abstract}

Published: 27 October 2009

Behavioral and Brain Functions 2009, 5:44 doi:10.1/86/1744-908I-5-44
Received: 16 August 2009

Accepted: 27 October 2009

This article is available from: http://www.behavioralandbrainfunctions.com/content/5/1/44

(C) 2009 Dufault et al; licensee BioMed Central Ltd.

This is an Open Access article distributed under the terms of the Creative Commons Attribution License (http://creativecommons.org/licenses/by/2.0), which permits unrestricted use, distribution, and reproduction in any medium, provided the original work is properly cited.

\begin{abstract}
Among dietary factors, learning and behavior are influenced not only by nutrients, but also by exposure to toxic food contaminants such as mercury that can disrupt metabolic processes and alter neuronal plasticity. Neurons lacking in plasticity are a factor in neurodevelopmental disorders such as autism and mental retardation. Essential nutrients help maintain normal neuronal plasticity. Nutritional deficiencies, including deficiencies in the long chain polyunsaturated fatty acids eicosapentaenoic acid and docosahexaenoic acid, the amino acid methionine, and the trace minerals zinc and selenium, have been shown to influence neuronal function and produce defects in neuronal plasticity, as well as impact behavior in children with attention deficit hyperactivity disorder. Nutritional deficiencies and mercury exposure have been shown to alter neuronal function and increase oxidative stress among children with autism. These dietary factors may be directly related to the development of behavior disorders and learning disabilities. Mercury, either individually or in concert with other factors, may be harmful if ingested in above average amounts or by sensitive individuals. High fructose corn syrup has been shown to contain trace amounts of mercury as a result of some manufacturing processes, and its consumption can also lead to zinc loss. Consumption of certain artificial food color additives has also been shown to lead to zinc deficiency. Dietary zinc is essential for maintaining the metabolic processes required for mercury elimination. Since high fructose corn syrup and artificial food color additives are common ingredients in many foodstuffs, their consumption should be considered in those individuals with nutritional deficits such as zinc deficiency or who are allergic or sensitive to the effects of mercury or unable to effectively metabolize and eliminate it from the body.
\end{abstract}




\section{Background}

Neuronal plasticity, the ability of neurons to undergo specific functional changes during the moments when learning takes place, appears to underlie learning capacity [1]. Neuronal plasticity is crucial to the creation and storage of long-term memory. Dysfunction of neuronal plasticity is a factor in poor neural development [2-5]. Abnormal neuronal plasticity also has also been implicated in mental retardation, and autism [2-5]. Essential nutrients, including trace minerals, amino acids, and fatty acids, are necessary for proper functioning of the central nervous system and play a role in the maintenance of normal neuronal plasticity. Specifically, dietary deficiencies of iron, zinc, iodine, selenium, copper, manganese, fluoride, chromium, and molybdenum are associated with mild to significant changes in neuronal function that can lead to poor health and adverse effects on behavior and learning [6].

Zinc deficiency related to dietary intake may be a factor in the development of several conditions that ultimately make learning more difficult for children. Such conditions include Autism Spectrum Disorders (ASD), Attention Deficit Hyperactivity Disorder (ADHD) and hyperactivity. In a recent review article, it was hypothesized that the increase in Autism may be related to transient maternal hypothyroxinemia resulting in low triiodothyronine (T3) in the fetal brain from insufficient dietary iodine intake and/or environmental exposure to antithyroid agents such as mercury [7]. Zinc deficiency, however, also lowers T3 [8] and may occur over time with the consumption of certain food chemicals such as high fructose corn syrup [9], tartrazine and sunset yellow $[10,11]$. The prevalence of low birth weight increased significantly in women in the United States (US) who had serum zinc levels in the lowest quartile [12], and low zinc intake during pregnancy is associated with a significant increase in the risk of preterm delivery [13]. Low birth weight and pre-term birth increase the risk of autism two fold [14]. Zinc is particularly crucial to a number of biological processes, and essential for neural development [15]. Poor nutrition leading to dietary deficiencies of zinc and/or other essential dietary nutrients such as selenium, amino acid methionine, and essential fatty acids can disrupt metabolic processes and impair brain function and neuronal plasticity by exacerbating heavy metal neurotoxicity $[1,16-18]$. There is evidence to suggest that the body's ability to maintain neuronal plasticity when essential dietary nutrients are lacking can be additionally impaired by exposure to environmental mercury. This article provides a review of such evidence and a model of how this toxic effect of mercury may occur (Figure 1).

The "Mercury Toxicity Model" in figure 1 is a flow chart of what can happen in the body when there is exposure to mercury. Neither the form of mercury nor the route of exposure is necessarily relevant for the purposes of this discussion. Exposure can occur via inhalation or ingestion; the model gives two examples of mercury $(\mathrm{Hg})$ exposure from ingestion of foods found in our environment (Hg in Fish and $\mathrm{Hg}$ in High Fructose Corn Syrup), without excluding other possible exposures such as $\mathrm{Hg}$ in ambient air. Upon exposure, in a healthy individual with adequate nutrition, metallothionein is expressed and mercury is eliminated from the body. If the individual consumes an unhealthy diet leading to mineral imbalances, especially zinc loss and copper gain, then it is possible that either there will not be enough metallothionein to eliminate the mercury or the metallothionein may not function properly. In either case, if the mercury is not eliminated then it will lead to oxidative stress. An important target organ of mercury regardless of form when it cannot be eliminated from the body is the brain. In the case of ingestion, bacteria and yeast in the gut may change inorganic mercury to organic methyl mercury, which is thought to pass through the blood brain barrier. In brain tissue organic mercury may then be converted back to inorganic mercury. Oxidative stress in the brain from mercury insult leads to reduced neuronal plasticity and this impairs learning. Mercury exposure via fish consumption is a special case. Fish is an important dietary food as it contains the fatty acids important for improved neuronal functioning and plasticity. However, if fish does not contain selenium in a $1: 1$ ratio with mercury and there is more mercury in the fish than selenium, then it is possible that consumption of the fish can disrupt the glutathione system leading to oxidative stress caused by mercury insult or other neurotoxins. Disruption in the glutathione system also reduces neuronal plasticity and impairs learning. Properly functioning metallothionein and glutathione systems are therefore required for mercury metabolism. This model is not perfect but the following review provides evidence to support the hypothesis, that if correct, cannot be ignored for very long.

\section{Sources of mercury exposure Mercury in the environment}

Mercury exposure, in its various forms, is thought to be a risk factor in causing some of the more prevalent neurological learning disorders, including autism [19]. A study of mercury in the environment and its correlation to pediatric neurodevelopmental disorders found that on average, for every 1,000 pounds of mercury (all forms) released into the environment via air emissions or wastewater effluent, as documented by the Environmental Protection Agency's Toxic Release Inventory, there was a 43percent increase in the rate of special education services and a 61-percent increase in the rate of autism [20]. In a more recent study, investigators of environmental mercury exposure found that for every 1,000 pounds of mer- 


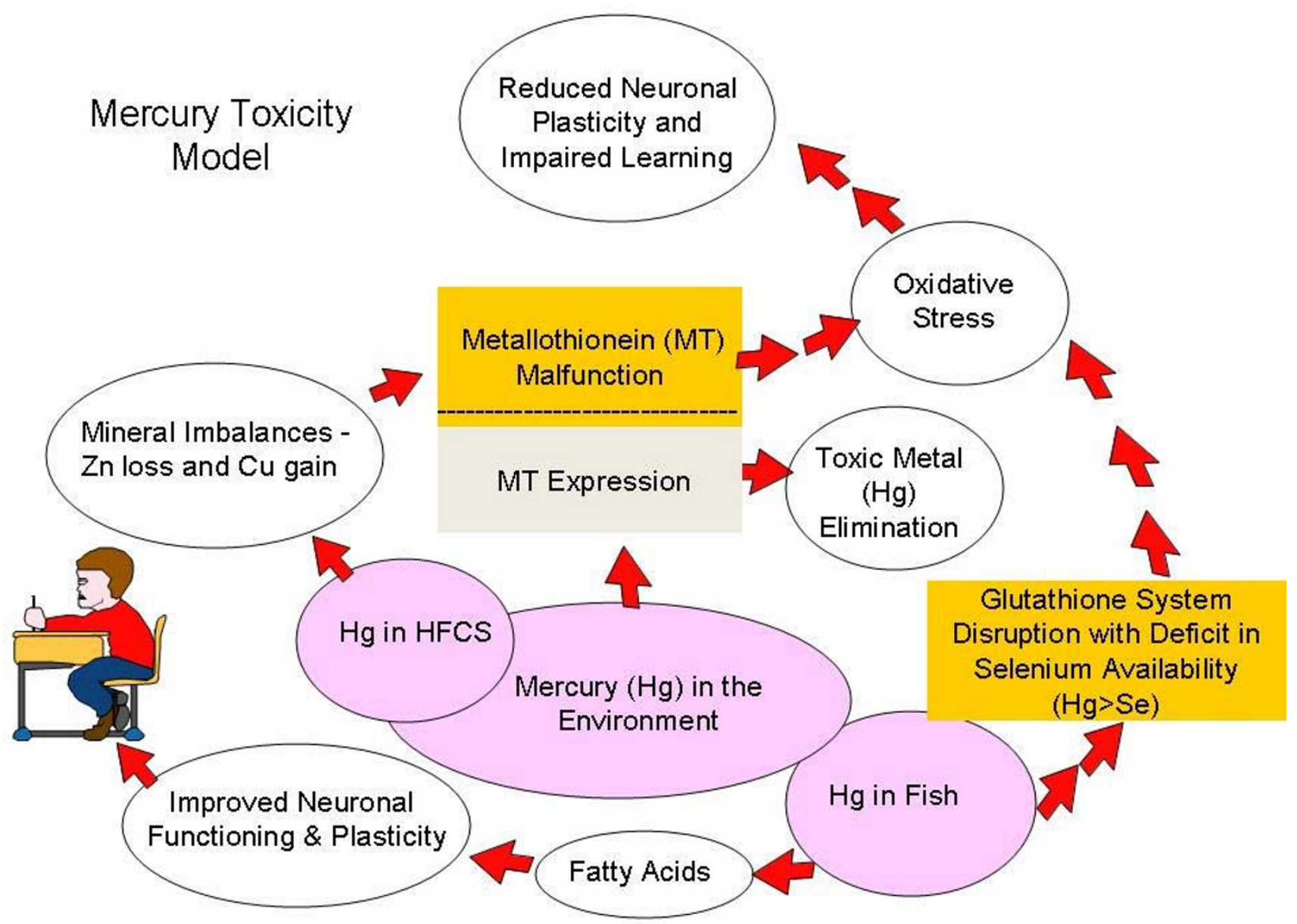

Figure I

Mercury Toxicity Model.

cury release, there is a $3.7 \%$ increase in autism rates of school age children living near coal fired power plants [21].

The presence of mercury in our environment will increase as long as humans continue to burn coal and use mercury to manufacture products (e.g., mercury amalgam, chloralkali chemicals, thermometers, thermostat switches). With respect to mercury emissions into the atmosphere, the United States Environmental Protection Agency (USEPA) estimates that about one third of US emissions are deposited within the contiguous US and the remainder enters the global cycle, of which the US contributes roughly three percent [22]. Current estimates are that less than half of all mercury deposition within the US comes from US emission sources. Mercury is therefore a transboundary issue and a global environmental contamination problem. In addition to the emissions from burning coal, mercury also enters the environment via wastewater from dental clinics using mercury amalgam and chlor- alkali chemical manufacturing plants using mercury cells. For environmental mercury levels to fall, there must be a worldwide effort to reduce mercury emissions from coalfired power plants and to reduce the use of mercury in products and manufacturing processes.

With respect to mercury cell chlor-alkali chemicals, there are approximately 50 manufacturing plants left worldwide. In the US, many plants have closed and most of them are now abandoned Superfund sites or undergoing corrective clean up action for mercury contamination [23]. The mercury contamination is a result of many years of mercury loss to the building infrastructure, atmosphere, surrounding soil, groundwater, and nearby streams. Clean up of these sites is slow often taking many years as mercury is continually released into the environment [23-25] and clean up technology is still under development [23]. The exact amount of mercury released from these abandoned sites each day remains unknown. The mercury cell chlor-alkali manufacturing plants still in 
operation in the US use approximately 80 tons of mercury every year to manufacture the chlor-alkali products caustic soda, chlorine, potash, and hydrochloric acid [26]. These chlor-alkali products all contain residual mercury [27] and are used by food, chemical, and pharmaceutical manufacturers to make thousands of other products [28]. Although only five plants now operate in the US, mercury cell chlor-alkali chemicals continue to be imported by US manufacturers to make their products [29]. Because of the magnitude of the use of mercury in manufacturing products, mercury and mercury-containing compounds from these products are found as a waste material in both household and industrial wastewater effluent and in sewage sludge that can then be applied to land as a fertilizer [30].

As mercury is discharged into the environment by different industrial processes and through the use of mercury contaminated chlor-alkali chemicals, humans become exposed via the water they drink, the air they breathe, and the foods they eat. Chen et al. found that human subjects living in a mercury contaminated region had a mean mercury concentration in serum nearly 40 times that of the control group and a mean mercury concentration in urine almost 75 times that of the control subjects living in a non-contaminated region [31]. The mercury in the contaminated region came from different sources: mercury mining and ore processing, coal combustion for power production, and chlor-alkali industries [31]. Chen et al. determined that the human subjects living in the contaminated region were primarily exposed to mercury via the inhalation of elemental mercury vapor and the consumption of mercury contaminated foodstuffs, which contained different mercury species or forms [31].

With regard to cumulative mercury exposure, there are multiple possible sources. These sources may include mercury as a pollutant in air, soil, dust, and water, a contaminant in foodstuffs and consumer products, a material in dental amalgam and lighting fixtures, and a contaminant in fish and seafood. Overall environmental mercury exposure includes all of these sources as "environment" includes home and office as well as the outdoors. Given the growing evidence of ongoing, cumulative environmental mercury exposure, it may be prudent to follow the American Academy of Pediatrics' guidelines for limiting exposure to all forms of mercury to help prevent neurodevelopmental problems in children [32].

\section{Methyl mercury in fish: a special consideration}

Fish is an important dietary source of omega-3 fatty acids that are required for normal neural development. However, fish can also be contaminated with mercury. (Figure 1.) According to the World Health Organization (WHO) and the Food and Drug Administration (FDA), concentra- tions of methylmercury ( $\mathrm{MeHg}$ ) in various species of fish cover a wide range, from less than $0.01 \mathrm{ppm}$ to over 3.0 ppm fresh weight, depending on factors such as $\mathrm{pH}$, the redox potential of the water, and the species, age and size of the fish $[33,34]$. Human hair analysis for mercury is a useful biomarker for determining long-term exposure to mercury from fish and non-fish food. Using data from the 1999-2000 National Health and Nutrition Examination Survey (NHANES), McDowell et al [35] found that total hair mercury is associated with age, race/ethnicity, and frequency of fish consumption. Analyses of blood from participants of the NHANES also found elevated mercury levels in women who were older, reported eating more fish, and who designated themselves in the "other" racial/ ethnic category (includes Asians, Native Americans, and Pacific Islanders [36,37]. With respect to chronic, lowlevel exposure to MeHg from maternal seafood consumption during pregnancy, there have been two studies published with conflicting results. In the Faroe Islands study, researchers found after following 900 children until seven years of age that higher umbilical cord blood $\mathrm{MeHg}$ was associated with lower scores on several developmental and cognitive tests [38]. This finding differs from the Seychelles Child Development study that found no association between total maternal hair mercury and the neurodevelopmental test performance demonstrated by 700 children, who were followed until up to nine years [39]. These differing findings have led to much controversy as to whether the risks of low-level MeHg exposure outweigh the benefits provided by omega- 3 fatty acids in fish. The controversy, however, is based on the assumption that dietary mercury exposures were the same for mothers who participated in the Seychelle and Faroe Island studies. Dietary mercury exposures for these two groups are not the same however. The Faroese diet includes whale meat and the Seychelles Islanders' diet does not [40]. In whale meat, the concentration of mercury rises continually with age and can exceed the selenium content [41]. Selenium is an important micronutrient needed to support glutathione function, which protects neurons from damage caused by mercury induced oxidative stress (figure 1). In fish, the concentration of mercury also rises continually with age but does not generally exceed the selenium content [42]. The Faroese diet of whale meat most likely contains more unmitigated mercury exposure with lower levels of selenium.

Studies suggest there is an interaction between mercury and selenium [43-46], however, it is unclear whether selenium protects from the toxic effects of mercury or mercury interferes with the benefits of selenium. It has been suggested that the formation of a 1:1 Hg-Se compound may explain the mercury detoxification by selenium [46]. In the study referenced earlier, Chen et al. reported serum 
selenium concentrations were significantly higher in the human subjects living in the mercury-contaminated region [31]. Specifically, with increased exposure to all forms of environmental mercury, serum selenium concentrations associated with glutathione peroxidase (GSH$\mathrm{Px}$ ) were 2 times higher in the mercury-exposed group than in the control group living in the non-contaminated area [31]. Further research is needed to determine how selenium and mercury interact when it comes to environmental mercury exposure or their concomitant consumption in fish or whale meat.

The results of a 2005 study found that, with moderate fish consumption during pregnancy, there was a benefit to offspring cognition, but that exposure to higher levels of mercury from fish led to adverse effects on child cognition [47] (Figure 1). The consensus now is that pregnant women do not need to avoid eating fish, but they need to choose varieties of fish with lower mercury concentrations [48]. Unfortunately, many species of fish have been compromised by MeHg contamination and the USEPA and the FDA have issued a joint advisory to pregnant women and others on the hazards of overconsuming contaminated commercial and non-commercial fish [49]. The most contaminated fish include king mackerel, swordfish, shark and tilefish.

Fish advisories for mercury in the US increased from 2,436 in 2004 to 3,080 in 2006. Thirty-five of fifty states have issued statewide fish advisories for methylmercury that suggest limiting consumption of certain fish and some include recommendations for safe levels of consumption and/or exposure [50]. These advisories often focus on the health effects of mercury exposure associated with neurodevelopmental harm and are therefore limited to the infant and women who are pregnant, nursing, or of reproductive age. No studies have been conducted to determine what effect fish consumption may have on sensitive populations such as children with attention deficit hyperactivity disorder (ADHD) or some form of autism spectrum disorder (ASD), however, clinical trials have been performed giving children with ADHD fish oil as a fatty acid supplement. The results of a study by Richardson and Puri are discussed in the last section of this article [51].

\section{Total mercury in high fructose corn syrup}

A key discovery related to the isomerization of dextrose in the 1960's led to the development of high fructose corn syrup (HFCS) by the corn refining industry [52]. HFCS is the end product from a corn wet-milling process that involves a number of steps in a product line that yields corn oil, animal feed, starch products, and corn sweeteners. Food manufacturers use HFCS as a sweetener to stabilize food products and enhance product shelf life [53].
Several chemicals are required to make HFCS, including caustic soda, hydrochloric acid, alpha-amylase, glucoamylase, isomerase, filter aid, powdered carbon, calcium chloride, and magnesium sulfate [54]. Up until recently, HFCS manufacturers used "mercury grade" caustic soda from mercury cell chlor-alkali plants to make their product and as a result consumers were likely exposed to low levels of mercury over time [55]. Using the results of analytical testing conducted on FDA collected samples of commercial HFCS for total mercury and the US per capita consumption of HFCS, Dufault et al. estimated daily mercury intakes from HFCS ranging up to 28 ug $[55,56]$. Consumption of mercury contaminated HFCS may have over time exceeded other major sources of mercury especially in high-end consumers of beverages sweetened with HFCS [55]. In response to the Dufault et al finding, the Corn Refiners Association stated in a news interview that the findings were outdated because they no longer use mercury cell chlor-alkali products in their manufacturing process [57]. This change in manufacturing practices has not been verified by a third party with nothing to gain outside of the corn industry and there are no regulations in place to prevent the future use of mercury cell chlor-alkali products in the HFCS manufacturing process. In any case, the data released by Dufault et al remain the only publicly available peer reviewed data. The Corn Refiners Association does not appear to dispute the fact that for many years, HFCS consumers were exposed to low levels of mercury in their diet from this product. HFCS is now ubiquitous in processed foods and significantly consumed by people all over the world. By the mid 1980's, when high fructose corn syrup had become the sweetener of choice by the soft drink beverage industry [52] as well as the manufacturers of many other processed food products, there was a corresponding rise in the prevalence of autism [58].

The rates of diagnosed Autism Spectrum Disorders are shown in Table 1 for California, the only State that reports number of cases dating back to the mid-1980s [59]. The annual net growth in cases ranges from $9 \%$ to $12 \%$ between 1987 and 2006-2007 and is consistent with growth found in other states in recent years. Annual growth rates of Autism Spectrum Disorder in California peaked in 2001 and 2002 at 19.6 and 19.4 percent respectively then declined to 11.8 percent in 2006 . Once a child is diagnosed with autism, the diagnosis is stable as is shown by the data from a longitudinal study by Lord and her colleagues [60]. In that study fewer than $6 \%$ of the children ages 2 to 9 had a reversal in the diagnosis. Similarly, in California, 94 percent of total persons with Autism Spectrum Disorders kept their diagnoses. Table 1 also shows the per capita consumption of high fructose corn syrup in pounds per year based on USDA estimates. The peak years for annual consumption of HFCS occurred 
Table I: Net Growth in Persons Diagnosed with Autistic Spectrum Disorders, CA Per Capita Consumption of High Fructose Corn Syrup, US, 1987-2006

\begin{tabular}{|c|c|c|}
\hline Year & $\begin{array}{l}\text { \% Growth } \\
\text { Autism }\end{array}$ & $\begin{array}{l}\text { Per Capita } \\
\text { Consumption } \\
\text { HFCS, Ib/yr }\end{array}$ \\
\hline 1987 & 9.0 & 34.0 \\
\hline 1988 & 10.8 & 34.9 \\
\hline 1989 & 11.3 & 34.3 \\
\hline 1990 & 10.9 & 35.3 \\
\hline 1991 & 10.4 & 35.8 \\
\hline 1992 & 8.5 & 36.9 \\
\hline 1993 & 12.9 & 38.8 \\
\hline 1994 & 13.5 & 40.0 \\
\hline 1995 & 13.4 & 41.0 \\
\hline 1996 & 16.8 & 41.1 \\
\hline 1997 & 17.2 & 43.0 \\
\hline 1998 & 17.2 & 44.1 \\
\hline 1999 & 16.2 & 45.4 \\
\hline 2000 & 18.3 & 44.6 \\
\hline 2001 & 19.6 & 44.6 \\
\hline 2002 & 19.4 & 44.8 \\
\hline 2003 & 13.5 & 43.4 \\
\hline 2004 & 12.1 & 42.7 \\
\hline 2005 & 10.6 & 42.2 \\
\hline 2006 & 11.8 & 41.5 \\
\hline
\end{tabular}

CA = California; US = United States; $\%=$ percent; HFCS = High

Fructose Corn Syrup; lb/yr = pounds per year

in 2000-2002 at 44.6 and $44.8 \mathrm{lbs} / \mathrm{yr}$ respectively, the same years as the peak for autism.

The decline in annual growth rates of Autism Spectrum Disorder in California could be explained by the reduction in annual per capita consumption of high fructose corn syrup or the reported reduction in the use of mercury cell chlor-alkali chemicals in the high fructose corn syrup manufacturing process. Whatever the case, there may be a biochemical connection between low level mercury exposures, zinc deficiency and the development of learning disorders such as ADHD and autism spectrum disorders. In a 1990 human study, researchers found that consumption of fructose and HFCS may lead to certain mineral imbalances including zinc loss and copper gain [9] (Figure 1). The human subjects demonstrated a reduction in numerical zinc balance and an increase in numerical copper balance when they were fed fructose and HFCS compared to the adjustment period [9]. This finding along with the more recent finding of the historic use of mercury in high fructose corn syrup [55] is of particular significance today with respect to neurodevelopmental disorders since there is now evidence that autism can be caused by a biochemical abnormality that disables the metal clearing function of the zinc dependent metallothionein (MT) protein [61-64] and zinc deficiency plays a role in ADHD [10,11]. Two mechanisms with the potential for disabling MT functioning include severe zinc depletion [65] and toxic metal overload [61-64]. Long term exposure to mercury contaminated high fructose corn syrup could produce both of these mechanisms and/or conditions that may disable MT functioning and lead to the bioaccumulation of mercury or other adverse neurological effect.

Children with Autism Spectrum Disorders have increased body burdens of mercury [66]. Because mercury inhibits cysteine ligands in the metal clearing metallothionein (MT) proteins that normally bind with metal ions such as copper and zinc [67], consumption of mercury-contaminated HFCS and other zinc depleting substances [10,11] over time by sensitive individuals may induce an MT malfunction (Figure 1). Such a malfunction may lead to severe zinc deficiency and allow copper to reach toxic levels in membranes leading to lipid peroxidation and cell damage [68] (Figure 1). Exposure of the brain to excessive oxidative stress may lead to a loss in learning capacity (Figure 1). Many children with ADHD are deficient in the micronutrient zinc $[69,70]$. Consumption of zinc depleting food additives [9-11] increases hyperactive behaviors (inattention, impulsivity, and over activity) both in children with extreme hyperactivity (i.e., ADHD) and in the general population [71]. Increased hyperactivity is associated with the development of educational difficulties especially in reading [72]. In rats, zinc deficiency along with oxidative stress predisposes the brain to damage by disruption of the blood-brain barrier [73] and prenatal zinc deficiency has pronounced effects on postnatal metallothionein metabolism, which can persist into adulthood [65]. With respect to consumption of high fructose corn syrup and adverse effect, Molteni et al. [74], found that a high fat, HFCS diet reduced brain-derived neurotrophic factor (BDNF) neuronal plasticity, and learning in 
rats. BDNF levels have been measured in human subjects with neurodevelopmental learning disorders. In 2006, Hashimoto et al. reported the serum levels of BDNF in human patients with autism were significantly lower than those of normal controls [75]. Shim et al. however, found mean plasma BDNF levels were significantly higher in 41 ADHD patients compared to 107 normal controls and suggested that plasma BDNF levels were positively associated with the severity of inattention symptoms [76]. Further studies will be required to understand the role of BDNF in either learning disorder.

As indicated by our toxicity model (figure 1), mercury may adversely affect learning if either metallothionein and glutathione metabolic functions are not functioning properly and supported by key dietary nutrients. Both of these metabolic functions are required by the body's immune system to combat mercury exposure. How the immune system responds to mercury insult is discussed in the section below.

\section{Nutritional deficiencies and metabolic disruptions in sensitive populations Amino acids and the glutathione system}

Essential amino acids, fundamental building blocks of proteins that provide the structural integrity of all living organisms, are provided by a diet rich in protein. Essential amino acids (those not produced endogenously) include histidine, isoleucine, leucine, lysine, methionine, phenylalanine, threonine, tryptophan, and valine. Essential amino acid deficiency can lead to adverse health effects. For instance, a deficiency of the essential amino acid methionine can adversely affect behavior and learning. Researchers found that 51 percent of autistic children showed evidence of methionine deficiency [77]. In a more recent study of 90 autistic children and 45 controls, mean plasma levels of methionine, cysteine, total glutathione, and the ratio of oxidized to reduced glutathione were significantly decreased among the autistic children [78]. Methionine acts as a precursor in the production of glutathione (GSH) in mammalian hepatocytes as a result of its conversion to cysteine [79]. James et al. found lower concentrations of methionine in the plasma of 20 autistic children compared to 33 control children without autism in a study published in 2004 [80].

GSH is the primary defense used by the neuron against free radicals. Depletion of GSH in rats can impair shortterm and long-term mechanisms of synaptic plasticity and stress the redox balance in the normal function of brain circuitry [81]. Metals, particularly copper and mercury, play a primary role in the initiation of reactive oxygen species and the depletion of GSH $[31,82]$.
The GSH system is effective at scavenging free radicals and serves as an oxidation reduction buffer that allows for the reduction of the highly reactive hydrogen peroxide $\left(\mathrm{H}_{2} \mathrm{O}_{2}\right.$; a byproduct of cellular respiration) to water. This prevents oxidative stress, which could lead to lipid peroxidation and cell damage $[83,84]$. In the reaction scheme illustrated in Figure 2, oxidation is potentiated by the catalyst glutathione peroxidase (GSH-Px) in which selenium plays a key role as an antioxidant cofactor. GSH-Px catalyzes the oxidation of reduced glutathione and allows for the reduction of hydrogen peroxide to water, preventing lipid peroxidation and cell damage $[31,83,85]$. Oxidized glutathione (GSSG) is reduced to GSH, a reaction catalyzed by glutathione reductase (GSH-Rx). Mercury or copper, shown as $\mathrm{M}^{\mathrm{n}}$ in Figure 2, can disrupt the GSH system, leading to cellular insult and potential apoptosis as a result of the generation of hydrogen peroxide [86]. Results from the recent study by Chen et al. of mercury-exposed humans suggest that mercury affects the bioavailability and retention of selenium and interferes with the metabolic processes dependent on selenium [31]. The researchers found that the serum selenium concentrations associated with GSH-Px and selenoproteins were 2 times higher in the mercury-exposed group than the control group [31]. A disruption of the GSH system by mercury leads to GSH depletion and cell destruction. An in vitro study of Jurkat $\mathrm{T}$ cells exposed to thiomersal demonstrated concentration-dependent apoptosis [87]. It was found that the mercury moiety, not the thiosalicylic acid moiety, of thiomersal was responsible for glutathione depletion [87]. GSH depletion is linked to several neurodegenerative disorders [88]. James et al. found lower concentrations of total GSH in the plasma of 20 autistic children compared to 33 control children without autism in a study published in 2004 [80]. In a recent study published in 2009, Sitta et al. found erythrocyte and plasma glutathione levels were significantly reduced in phenylketonuric patients compared to a control group [89]. When the GSH system is upset by the presence of mercury, changes in the immune system occur. Mercury exposure activates the glucocorticoid anti-inflammatory response $[90,91]$. Glucocorticoids enhance the neurotoxicity of reactive oxygen species by decreasing the activity of glutathione peroxidase. This results in a negative feedback loop that depletes GSH and exacerbates the apoptotic process [92,93] (Figure 2). The glucocorticoid antiinflammatory response also induces MT expression in the presence of mercury [91,93-96].

\section{Metallothionein: a protein for metal elimination}

MTs represent a family of ubiquitous, low-molecularweight, metal-binding proteins that have a molecular mass of less than 7,000 Daltons, containing approximately 33-percent cysteine residues [94]. Due to their binding capacity (i.e., up to seven zinc or 12 copper ions 


\section{Oxidation and Reduction of the Glutathione System}

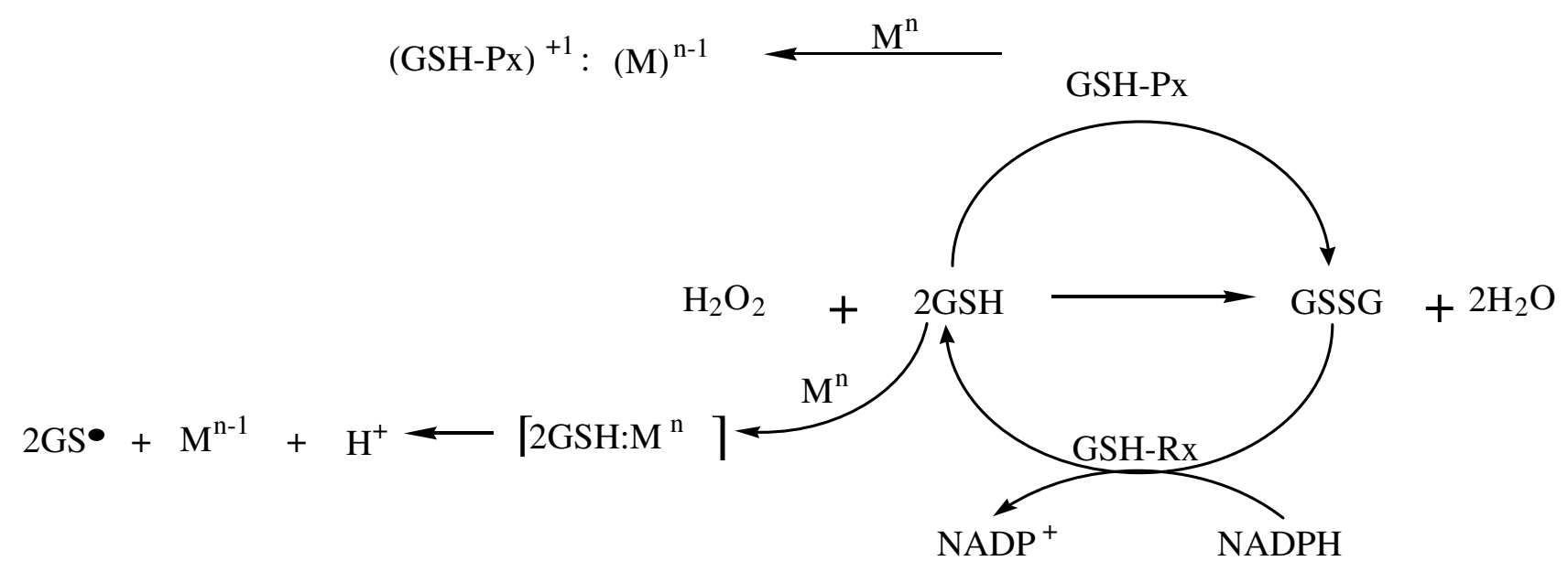

Figure 2

Oxidation and Reduction of the Glutathione System.

per molecule) and ubiquitous nature, it has been suggested that MTs may engage in essential metal trafficking to and from many metal-dependent proteins [91]. MTs are involved in many important processes such as the regulation of zinc homeostasis, necessary for proper enzyme function [95-97]. Although as many as 18 different metals may be associated with an MT molecule, only copper, cadmium, lead, silver, mercury, and bismuth are capable of displacing a zinc atom [94]. All of these known environmental toxicants cause MT expression [94]. MTs are among the body's primary protective molecules against toxic metals $[68,98]$. In mice, MT provides a survival benefit in stressful situations, such as heavy metal and free radical exposure, inflammation, and zinc or other nutrient deficiency [94]. The protective effect of MT against the toxicity of cadmium and mercury vapor has been the most studied thus far [99-102].

Besides toxic metal exposure, the MT gene family is also induced by bacterial cell wall lipopolysaccharides and inflammatory cytokines (such as interleukin-1beta), collectively playing a major neuroprotective role against these various environmental insults. Constitutive cellular abundance of MTs $-1,-2,-3$ and -4 (the latter specifically localized to stratified squamous epithelium) are therefore an important index of a tissue's susceptibility, and capability to handle a wide array of toxic insults. As the nasal cavity, primary olfactory neurons at the cribiform plate, and anatomically connected olfactory bulb are continu- ally exposed to various airborne pollutants in the external environment, the olfactory system provides a direct route of entry into the central nervous system for an assortment of environmental neurotoxic agents including mercury. It is therefore not surprising that the olfactory system has one of the highest MT abundances of the mammalian central nervous system, and that expression of the MT-1, -2, and especially -3 isoforms are greatest in the olfactory neurons of the brain and the anatomically adjacent hippocampal region, which has direct nerve fiber projection contacts from the olfactory bulb [94,101,103-105]. In mercury vapor intoxicated mice, MT-3 expression was found to dominate in the olfactory cells of the olfactory mucosa as well as in neurons of the olfactory bulb, while MT-1 and -2 immunoreactivity predominated in supporting basal and acinar cells of the Bowman's gland of the olfactory mucosa [101].

MT-3 is a brain specific, high zinc containing MT, which is found in neuronal and glial cells [94,101,104-107]. Researchers examined 503 patients with autistic spectrum disorders and found lower levels of MT with significantly higher copper: zinc ratios in the autistic group compared to healthy age- and gender-matched controls [77]. Three peer reviewed papers published in 2009 report findings that support the link between low-dose mercury exposure and metallothionein dysfunction and an association with ASD [62-64]. It has been theorized that MTs may serve as a redox control and the fact that MT-3 is relatively high in 
zinc and is associated with neurons provides evidence that it fills a role as an oxidation-reduction buffer in neuronal tissue. Importantly, the MT protein in the immune system may not function properly if either zinc or methionine are deficient in the diet $[108,109]$. Consumption of any substance leading to zinc loss and copper gain (e.g. HFCS) or zinc deficiency (e.g. tartrazine and sunset yellow food dye) should be avoided by sensitive populations such as children diagnosed with ASD, ADHD or found to be zinc deficient.

\section{Fatty acids and neuronal functioning}

Omega-3 fatty acids have been found to be a basic component of normal neural development and maintenance of neural plasticity [110]. Dietary sources of omega-3, however, are not plentiful in plant foods with the exceptions of flax (Linum usitatissimum) and Chia (Salvia hispanica) seeds, and are found in small amounts in walnuts, soybeans, canola oil, and free-range chicken eggs [110]. The only rich sources of omega-3 fatty acids are cold water fish (e.g., anchovies, krill, herring, tuna, mackerel, salmon, and sardines), cod liver oil, and other fish oils. Deficiencies of two important omega-3 fatty acids, eicosapentaenoic acid (EPA) and docosahexaenoic acid (DHA), commonly lead to adverse health effects and have been found in children with behavior disturbances [111,112].

The role of DHA in brain development and visual acuity has been extensively studied [113]. The breast milk of nursing mothers contains adequate amounts of DHA if dietary intake is sufficient [113]. There is a preponderance of evidence that shows infants fed unfortified formula have poorer vision and lower IQs than infants fed formula fortified with DHA [113]. In 1993, the WHO recommended that pre-term and term infant formulas include DHA and in 2001, FDA allowed a manufacturer's self-declaration that DHA and arachidonic acid (AA) were generally recognized as safe (GRAS) for use in infant formula [114]. In 2002, infant formula manufacturers began marketing infant formulas containing DHA and AA in the US.

DHA protects neurons and glia from death, in part, by maintaining BDNF, which is a small protein, made within the brain that is crucial for maintaining neuronal plasticity $[115,116]$. Wu et al. [117] found that dietary omega-3 fatty acids in the form of DHA not only normalize BDNF but also reduce oxidative damage and counteract learning disability after traumatic brain injury in rats. Oxygenated DHA-derivatives, including a recently described form of modified DHA called neuroprotectin D1, have been shown to promote brain cell survival via the induction of highly specific brain gene expression programs that confer strong resistance to apoptosis and potent neuroprotection [118].
Researchers have been investigating the link between essential fatty acids and ADHD in children. Stevens et al. [119] found that 53 children with ADHD had significantly lower plasma levels of omega- 3 fatty acids than did the control group of 43 children. The authors noted that the children with the worst symptoms of essential fatty acid deficiency increased thirst, frequent urination, dry hair and skin - had the lowest plasma levels of omega-3 fatty acid levels. Another study, conducted by Mitchell et al. [120], compared 44 hyperactive children with 45 ageand sex-matched controls. DHA levels were significantly lower in the hyperactive children, who also had auditory, visual, language, reading, and learning difficulties, and lower average birth weight compared to controls. Colter et al. [121] also found low levels of DHA and total omega-3 fatty acids in ADHD children compared with controls. In an effort to raise DHA levels, Voight et al. [122] administered $345 \mathrm{mg}$ per day of DHA to 27 children with ADHD without any significant improvement in behavior compared to the 27 children who served as controls. Hirayama et al. [123] used a higher dose of DHA (514 mg per day) than the previous study and also found no improvement in the DHA group.

Despite the fact that low levels of DHA were found in children with ADHD, supplementing with DHA alone or in high amounts relative to other essential fatty acids (EFAs) have not been shown to be effective in improving behavior. Researchers have begun to look at other fatty acids and found that a combination of EFAs and in particular EPA may be more effective in the modulation of behavior disorders. Forty-one children with learning difficulties were randomly assigned to supplementation with EPA $186 \mathrm{mg}$, DHA $480 \mathrm{mg}$, gamma linolenic acid (GLA) 96 $\mathrm{mg}$, linoleic acid $864 \mathrm{mg}$, and AA $42 \mathrm{mg}$ or placebo (olive oil) for 12 weeks [51]. The group receiving the fish oil supplement had significant improvements in learning and behavioral scores and other ADHD-related symptoms compared to the group given olive oil [51]. (Figure 1.) In a later study, 117 children with developmental coordination disorder were given either $558 \mathrm{mg}$ EPA, $174 \mathrm{mg}$ DHA, and $60 \mathrm{mg}$ GLA or placebo [124]. The children receiving the fish oil supplement demonstrated significant improvements in reading, spelling, and behavior after three months of treatment compared to placebo [124]. In an open-label pilot study, Sorgi et al. [125] gave a high dose EPA/DHA supplement containing $10.8 \mathrm{~g}$ of EPA and $5.4 \mathrm{~g}$ of DHA per day to 9 children for eight weeks. They found significant improvements in behavior including inattention, hyperactivity, oppositional behavior and conduct disorder. Sinn and Bryan [126] administered 558 mg EPA, $174 \mathrm{mg}$ DHA and $60 \mathrm{mg}$ GLA/day to 36 children for 15 weeks and improvements were found for inattention and hyperactivity and impulsivity compared with the control group. Recently both Johnson et al. [127] and 
Belanger et al. [128] found improvement in inattention in a subgroup of children with ADHD when supplemented with a mixture of these essential fatty acids.

EPA and DHA are both essential for optimal brain function, but for different reasons. DHA is important for the structure of the neuronal membranes, while EPA plays a role in brain function by regulating neuronal signaling, neurotransmitter uptake, and the activity of phospholipase enzymes. EPA has been shown to reduce the overactivity of phospholipase $A_{2}$ which in excess can deplete the phospholipids of the long chain polyunsaturated fatty acids critical to normal brain function. EPA may be a useful adjunct in the treatment of various neurological conditions including depression, bipolar disorder, schizophrenia, dyslexia, dyspraxia, ADHD, and Autism Spectrum Disorders [112,129,130].

Magnesium and zinc are needed to help convert the 18carbon, plant-derived essential fatty acids (EFAs) to long chain fatty acids, notably DHA and EPA [131]. Many children with ADHD are deficient in these nutrients and may therefore have difficulty elongating the 18-carbon fatty acids [132]. In a sample of 116 children with ADHD, researchers found that 95 percent had a magnesium deficiency [133]. In 1997, researchers found that a combination of magnesium aspartate and magnesium lactate supplemented at a dose of $200 \mathrm{mg}$ daily for six months significantly reduced disruptive behavior in children with ADHD compared to a control group [134]. Galland [135] found an impaired desaturation of polyunsaturated fatty acid in a magnesium compromised population. This desaturation enzyme is magnesium dependent. Mahfouz et al. [136] found a significant reduction in long chain polyunsaturated fatty acids in magnesium deficient cells pointing to an impairment of delta 5 and/or delta 6 desaturase enzymes. It is possible that correcting a magnesium deficiency may restore desaturase enzyme function. Researchers also found that deficient levels of zinc are more commonly found in children with ADHD and supplementing these children with zinc significantly reduced hyperactivity, impulsivity, and impaired socialization scores, especially in children with low levels of EFAs $[137,138]$.

Children who have difficulty converting EFAs to long chain fatty acids can obtain a preformed source of EPA and DHA as a nutritional supplement or in the diet by consuming fish or fish oil. As discussed above, cold-water fish provide the only rich dietary source of these omega-3 fatty acids; however, recent research on trace metal contamination has questioned their safety. Guallar et al. [139] found, for instance, that the cardio protective benefits of fatty fish may be compromised by their high mercury content. Canadian researchers found a significant association between high levels of mercury and EPA in the blood of children (consistent with high levels of fish consumption) [140]. In addition, the researchers found a statistically significant inverse association between attentional focusing and blood mercury levels in children under age three years of age [140]. A careful selection of fish with low mercury and high EFA content, such as salmon and sardines, is essential in minimizing exposure to mercury while increasing consumption of these important EFAs. With respect to the consumption of fish oil or other supplements that are fish-derived, caution is warranted, as mercury contamination may be possible. Out of 100 samples of fish oil dietary supplements analyzed for mercury by the Food Standards Agency in the United Kingdom, nine were found to contain mercury above the limit of detection of $0.0014 \mathrm{mg} / \mathrm{kg}$ [141].

\section{Key issues related to mercury exposure guidelines}

While the total dietary intake of mercury is not known, mercury is widely accepted to be an unusually toxic heavy metal and the American Academy of Pediatrics has recommended that minimizing exposure to any form of mercury is essential for optimal child health [32]. The current recommendation for "safe" mercury consumption is based on a "reference dose" or RfD from fish consumption and only applies to methyl mercury ( $\mathrm{MeHg}$ ). The USEPA and FDA define the RfD as " [a]n estimate (with uncertainty spanning perhaps an order of magnitude) of a daily oral exposure to the human population (including sensitive subgroups) that is likely to be without an appreciable risk of deleterious effects during a lifetime." The current official RfD for methyl mercury in the US is set at 1 ppm although EPA has historically pushed for a lower reference dose of $0.1 \mathrm{ppm}$. Unfortunately, this official "reference dose" of $1 \mathrm{ppm}$ does not take into consideration what the human body needs nutritionally to successfully metabolize and excrete methyl mercury, and it only applies to MeHg exposure.

With regard to total mercury exposure, the Joint Expert Committee on Food Additives (JECFA) recommends an exposure limit of 1 ppm for mercury in their 2005 Evaluation of Food Additives report [142]. This report does not specifically address the mercury content in the food color additives tartrazine also known as FD\&C Yellow 5 or sunset yellow also known as FD\&C Yellow 6 but these chemicals are manufactured with the chlor-alkali product "hydrogen chloride" and may not contain more than 1 ppm mercury according to US Food and Drug Administration regulations [143]. In addition to causing zinc deficiency, both of these food color additives have been linked to hyperactivity in children [71] and the United Kingdom has asked manufacturers to voluntarily ban their use in food products [144]. 


\section{Etiology of ASD and ADHD}

In 2007 alone, there were 1000 studies published on all aspects of ASD [145]. As is the case with ADHD, there are likely unknown and unmeasured variables associated with the development of ASD. Disease related and/or exposure related bias arises when there is a causal or associational path of no interest to the researchers [146]. In this review article we have clearly not identified all of the possible variables associated with the development of these two disease conditions. The development of ASD and ADHD likely involve a broad range of genetic, prenatal, social, developmental, nutritional and environmental factors $[145,147]$. We have focused primarily on some of the nutritional factors that may be considered along with environmental mercury exposure in the development of treatment plans for patients with ASD or ADHD. Multiple treatment modalities are most likely needed to treat these patients successfully [147].

\section{Conclusion}

Adequate nutrition, specifically omega-3 fatty acids, methionine, and the trace minerals zinc and selenium are important for maintaining neuronal plasticity and learning capacity. The evidence does suggest that improper or inadequate nutrients may lead to behavior and learning disorders when mercury is present in the environment. Because current standards allow the use of mercury cell chlor-alkali chemicals in food manufacturing, food products that are made with one or more of these ingredients may contain trace amounts of mercury such as is the case for HFCS and other food additives. These low-level mercury exposures may contribute to cumulative environmental mercury exposure and present a problem for sensitive individuals who do not have adequate levels of glutathione and metallothionein and/or are deficient in the trace minerals needed for metal metabolism. Because consumption of HFCS and other food additives may lead to trace mineral imbalances and/or zinc deficiency, further research is needed to determine whether or not these food ingredients are safe for consumption by sensitive populations. If food manufacturers continue to use mercury grade chlor-alkali chemicals, it may be necessary to account for this source of mercury exposure in dietary guidelines for sensitive populations such as children with ADHD and autism spectrum disorders. In addition, consideration of dietary micronutrients required to enhance neurological development and support proper functioning of metallothionein, glutathione peroxidase, and other metal clearing and detoxifying mechanisms in the brain seems warranted.

\section{List of abbreviations}

ASD: Autism Spectrum Disorder; ADHD: attention deficit hyperactivity disorder; T3: tri-iodothyronine; US: United States; USEPA: United States Environmental Protection
Agency; WHO: World Health Organization; FDA: Food and Drug Administration; MeHg: methylmercury; NHANES: National Health and Nutrition Examination Survey; GSH-Px: glutathione peroxidase; HFCS: high fructose corn syrup; ug: micrograms; MT: metallothionein; BDNF: brain-derived neurotrophic factor; GSH: glutathione; GSSG: oxidized glutathione; GSH-Rx: glutathione reductase; EPA: eicosapentaenoic acid; DHA: docosahexaenoic acid; AA: arachidonic acid; GRAS: generally recognized as safe; GLA: gamma linolenic acid; EFAs: essential fatty acids; mg/kg: milligrams/kilogram; RfD: reference dose; ppm: parts per million; JECFA: Joint Expert Committee on Food Additives.

\section{Competing interests}

The authors declare that they have no competing interests.

\section{Authors' contributions}

RD spearheaded the review and recruited interdisciplinary collaborators to contribute to the development of the manuscript. RD was the lead environmental investigator and literature reviewer for the sources of mercury exposure section. LP and BL both contributed greatly to the development of the amino acids and glutathione system section. WL was the lead investigator and reviewer for the metallothionein section. RS was the lead investigator and reviewer for the fatty acids section. RC reviewed, analyzed, and prepared the epidemiological data. CC, DW, and SG were instrumental in editing the manuscript and reviewing it critically for intellectual content. All authors read and approved the final manuscript.

\section{Acknowledgements}

The authors would like to thank Dr. William Walsh for his kind feedback on the role of micronutrients in learning disorders, and Dr. Howard Hu, Dr. Lori Brown, Dr. Laura Raymond, Dr. Rao Ivaturi, Dr. Peter Green, Dr. Kathryn Mahaffey, and Dr. Martha Herbert for their helpful reviews over the years.

\section{References}

I. Dauncey MJ, Bicknell RJ: Nutrition and neurodevelopment: mechanisms of developmental dysfunction and disease later in life. Nutr Res Rev 1999, 1 2:231-253.

2. Dong WK, Greenough WT: Plasticity of nonneuronal brain tissue: roles in developmental disorders. Ment Retard Dev Disabil Res Rev 2004, 1 0:85-90.

3. Lee YS, Silva AJ: The molecular and cellular biology of enhanced cognition. Nat Rev Neurosci 2009, I 0(2): 126-140.

4. Tsanov M, Manahan-Vaughn D: Synaptic plasticity from visual cortex to hippocampus: systems integration in spatial information processing. Neuroscientist 2008, I 4(6):584-597.

5. Howland JG, Wang YT: Synaptic plasticity in learning and memory: stress effects in the hippocampus. Prog Brain Res 2008, 169:145-158.

6. Hubbs-Tait L, Nation JR, Krebs NF, Bellinger DC: Neurotoxicants, micronutrients, and social environments. PSPI 2005, 6(3):57-|2I.

7. Roman GC: Autism: transient in utero hypothyroxinemia related to maternal flavonoid ingestion during pregnancy and to other environmental antithyroid agents. I Neurol Sci 2007, 262:15-26. 
8. Morley JE, Gordon J, Hershman JM: Zinc deficiency, chronic starvation, and hypothalamic-pituitary-thyroid function. Am J Clin Nutr 1980, 33(8): I767-70.

9. Ivaturi R, Kies C: Mineral balances in humans as affected by fructose, high-fructose corn syrup, and sucrose. Plant Foods for Hum Nutr 1992, 42(2): |43-I51.

10. Ward NI, Soulsbury K, Zettel VH, Colquhoun ID, Bunday S, Barnes $B$ : The influence of the chemical additive tartrazine on the zinc status of hyperactive children-a double-blind placebocontrolled study. J Nutr Med 1990, I:5 I-57.

II. Ward NI: Assessment of chemical factors in relation to child hyperactivity. I Nutr Environ Med 1997, 7:333-342.

12. Neggers YH, Cutler GR, Action RT, Alvarej JA, Bonner JL, Goldenberg RL, Go RCP, Roseman JM: A positive association between maternal serum zinc concentration and birth weight. $\mathrm{Am}$ Clin Nutr 1990, 5 I:678-684.

13. Scholl TO, Hediger ML, Schall Jl, Fischer RL, Khoo CS: Low zinc intake during pregnancy:its association with preterm and very preterm delivery. Am J Epidemiol I993, I 37( I 0): I I I5- I I 24.

14. Schendel D, Karapurkar Bhasin T: Birth weight and gestationa age characteristics of children with autism, including a comparison with other developmental disabilities. Pediatrics 2008 , I 2 I(6): I | 55- | | 64.

15. Sandstead $\mathrm{HH}$ : Causes of zinc and iron deficiencies and their effects on the brain. J Nutr 2000, I 30:347-349.

16. Chapman L, Chan HM: The influence of nutrition on methylmercury intoxication. Environ Health Perspect 2000, I08(Suppl I): $29-56$

17. Clarkson TW, Strain J: Nutritional factors may modify the toxic action of methylmercury in fish-eating populations. $J$ Nutr 2003, I33(Suppl I): I539-I543.

18. Peraza MA, Ayala-Fierro F, Barber DS, Casarez E, Rael LT: Effects of micronutrients on metal toxicity. Environ Health Perspect 1998, I 06(Suppl I):203-2I6.

19. Institute for Children's Environmental Health [http:// www.iceh.org/pdfs/LDDI/LDDIStatement.pdf]

20. Palmer R, Blanchard S, Stein Z, Mandell D, Miller C: Environmental mercury release, special education rates, and autism disorder: an ecological study of texas. Health Place 2006, I 2:203-209.

21. Palmer R, Blanchard S, Wood R: Proximity to point sources of environmental mercury release as a predictor of autism prevalence. Health Place 2008.

22. Environmental Protection Agency [http://www.epa.gov/mer cury/control emissions/global.htm]

23. Environmental Protection Agency, Office of Superfund Remediation and Technology Innovation [http://www.epa.gov/ tio/download/remed/542r07003.pdf]

24. Bravo AG, Loizeau JL, Ancey L, Ungureanu VG, Dominik J: Historical record of mercury contamination in sediments. Environ Sci Pollut Res Int 2008, I 6( I 66-75 [http://www.springerlink.com/content/ 6x6677/8u23555I5/fulltext.pdf].

25. Neculita CM, Zagury GJ, Deschenes L: Mercury speciation in highly contaminated soils from chlor-alkali plants using chemical extractions. J Environ Qual 2005, 34:255-262.

26. Environmental Protection Agency [http://www.epa.gov/ord/ NRMRL/pubs/600r02104/600r02104chap3.pdf]

27. Chlorine Institute [http://www.chlorineinstitute.org/files/PDFs/ EPA 2005 Annual Report Final.pdf

28. Chlorine Institute [http://www.chlorineinstitute.org/Stewardship/ AboutChlorine.cfm?navltemNumber $=3495$ ]

29. United States International Trade Commission [http:// www.usitc.gov/]

30. Van Loon JC: Agricultural use of sewage treatment plant sludges, a potential source of mercury contamination. Environ Lett 1973, 4:259-265.

31. Chen C, Yu H, Zhao J, Li B, Qu L, Liu S, Zhang P, Chai Z: The roles of serum selenium and selenoproteins on mercury toxicity in environmental and occupational exposure. Environ Health Perspect 2006, I | 4(2):297-30 I.

32. Goldman LR, Shannon MW: American academy of pediatrics technical report: mercury in the environment: implications for pediatricians. Pediatrics 200I, I08(I):197-205

33. World Health Organization [http://www.inchem.org/docu ments/ehc/ehc/ehcl0I.htm]

34. Food and Drug Administration [http://www.cfsan.fda.gov/ frf/ sea-mehg.html]
35. McDowell MA, Dillon CF, Osterloh J, Bolger PM, Pellizzari E, Fernando R, Montes de Oca R, Schober SE, Sinks T, Jones RL, Mahaffey KR: Hair mercury levels in U.S. children and women of childbearing age: reference range data from NHANES 1999. 2000. Environ Health Perspect 2004, I I 2( I I): I I 65- I I 7 I.

36. Hightower J, O'Hare A, Hernandez G: Blood mercury reporting in NHANES: identifying asian, pacific islander, native american, and multiracial groups. Environ Health Perspect 2006, I |4(2): I73-I75.

37. Mahaffey KR, Clickner RP, Bodurow CC: Blood organic mercury and dietary mercury intake national health and nutrition examination survey, 1999 and 2000. Environ Health Perspect 2004, I I 2(5):562-570.

38. Grandjean P, Weihe P, White RF, Debes F, Araki S, Yokoyama K Murata K, Sorensen N, Dahl R, Jorgensen PJ: Cognitive deficit in 7 year-old children with prenatal exposure to methylmercury. Neurotoxicol Teratol 1997, 19:417-428.

39. Davidson PW, Myers G], Cox C, Axtell C, Shamlaye C, Sloane-Reeves J, Cernichiari E, Needham L, Choi A, Wang Y, Berlin M, Clarkson TW: Effects of prenatal and postnatal methylmercury exposure from fish consumption on neurodevelopment outcomes at 66 months of age in the Seychelles Child Development Study. JAMA 1998, 280:701-707.

40. Raymond LJ, Ralston VC: Mercury: selenium interactions and health implications. Seychelles Medical and Dental Journal 2004, 7(Special I):72-77.

41. Julshamn K, Anderson A, Ringdal O, Morkore J: Trace elements intake in the faroe islands - element levels in edible parts of pilot whales (globicephalus meleanus). Sci Total Environ 1987, 65:53-62.

42. Lourdes MA, Culvin-Aralar A, Furness RW: Mercury and selenium interactions: a review. Ecotoxicol Environ Saf 1991, 2 I:348-364.

43. Ganther HE: Selenium: relation to decreased toxicity of methylmercury in diets containing tuna. Science 1972, 175: I I22-I I24

44. Ohi G, Nishigaki S, Seki H, Tamura Y, Maki T: Efficacy of selenium in tuna and selenite in modifying methylmercury intoxication. Environ Res 1976, 12:49-58.

45. Spiers R, Spiers M: Proceedings of Clerc 2nd Annual Symposium: 24 October 1998 University of California at Davis; 1998.

46. Vasconcellos M, Bode P, Paletti G: Determination of mercury and selenium in hair samples of brazilian Indian populations living in the amazon region by neutron activation analyses. Proceedings of the International Symposium on Trace Elements in Humans: New Perspectives, 3rd, 4-6 October 200I. Athens, Greece 200I.

47. Oken E, Wright RO, Kleinman KP, Bellinger D, Amarasiriwardena CJ, Hu H, Rich-Edwards JW, Gillman MW: Maternal fish consumption, hair mercury, and infant cognition in a U.S. cohort. Environ Health Perspect 2005, I I 3( I 0): I 376- I 380.

48. Association for Reproductive Health Professionals [http:// www.arhp.org/publications-and-resources/quick-reference-guidefor-clinicians/fish-and-health/summary]

49. Food and Drug Administration [http://www.cfsan.fda.gov/ dms/ admehg3.html]

50. Environmental Protection Agency [http://www.epa.gov/water science/fish/advisories/2006/index.html]

51. Richardson AJ, Puri BK: A randomized double-blind, placebocontrolled study of the effects of supplementation with highly unsaturated fatty acids on ADHD-related symptoms in children with specific learning difficulties. Prog Neuropsychopharmacol Biol Psychiatry 2002, 26(2):233-239.

52. Pioneer [http://www.pioneer.com/CMRoot/Pioneer/end use/ industryselect/marketplace/wet milling.pdf]

53. Corn Refiners Association [http://www.corn.org/HFCSBro chure.pdf]

54. Lurgi Life Science GmbH: High fructose syrup production-process and economics. In Proceedings of International Conference on Value-Added Products for the Sugar Industry Baton Rouge, LA; 1999.

55. Dufault R, LeBlanc B, Schnoll R, Cornett C, Schweitzer L, Wallinga D, Hightower J, Patrick L, Lukiw W: Mercury from chlor-alkali plants: measured concentrations in food product sugar. Environ Health 2009, 8:2.

56. United States Department of Agriculture [http:// www.ers.usda.gov/briefing/sugar/data/table52.xls] 
57. Star Tribune [http://www.startribune.com/lifestyle/health/ 38430359.html?elr=KArks7PYDiaK7DUvDE7aL V BD77:DiiUiacyK Unciaec807EyUr]

58. Newschaffer C, Falb M, Gurney J: National autism prevalence trends from united states special education data. Pediatrics 2005, I I 5(3):277-282.

59. California Department of Developmental Services [http:// www.dds.ca.gov/AUTISM/docs/AutismReport 2007.pdf]

60. Lord C, Risi S, DiLavore PS, Shulman C, Thurm A, Pickles A: Autism from 2 to 9 years of age. Arch Gen Psychiatry 2006, 63:694-70I.

61. Walsh WJ, Usman A, Tarpey J: Disordered metal metabolism in a large autism population. Proceedings of the Amer Psych Assn; New Research: Abstract NRI09; May 2001; New Orleans, LA 2001.

62. Faber S, Zinn GM, Kern JC, Kingston HM: The plasma zinc/serum copper ratio as a biomarker in children with autism spectrum disorders. Biomarkers 2009, I4(3): $17 \mid-180$.

63. Blaylock RL: A possible central mechanism in autism spectrum disorders, part 2: immunoexcitotoxicity. Altern Ther Health Med 2009, I 5 (I):60-67.

64. Minami T, Miyata E, Sakamoto Y, Yamazaki H, Ichida S: Induction of metallothionein in mouse cerebellum and cerebrum with low-dose thiomerosal injection. Cell Biol Toxicol 2009 in press.

65. Vruwink KG, Hurley LS, Gershwin ME, Keen CL: Gestational zinc deficiency amplifies the regulation of metallothionein induction in adult mice. Proceedings of the Society for Experimental Biology and Medicine. Society for Experimental Biology and Medicine 1988, I 88(I):30-34.

66. Geier D, Geier M: A prospective study of mercury toxicity biomarkers in autism spectrum disorders. J Toxicol EnvironHealth A 2007, 70: 1723-1730.

67. Ladner L, Lindstrom L: Copper in society and the environment. 2nd revised edition Environmental Research Group (MFG); 1999.

68. Olanow CW, Arendash GW: Metals and free radicals in neurodegeneration. Curr Opin Neurol 1994, 7(6):548-558.

69. Konofal E, Lecendreux M, Arnulf I, Mouren MC: Iron deficiency in children with attention-deficity/hyperactivity disorder. Arch Pediatr Adolesc Med 2004, I 58( I 2): I I I3- I I I5.

70. Starobrat-Hermelin B: The effect of deficiency of selected bioelements on hyperactivity in children with certain specified mental disorders. Ann Acad Med Stetin 1998, 44:297-3I4.

7I. McCann D, Barrett A, Cooper A, Crumpler D, Dalen L, Grimshaw K, Kitchin E, Lok K, Porteus L, Prince E, Sonuga-Barke E, Warner JO, Stevenson J: Food additives and hyperactive behavior in 3year-old and 8/9-year-old children in the community: a randomized, double-blinded placebo-controlled trial. Lancet 2007, 370(9598): I560-I567.

72. McGee R, Prior M, Williams S, Smart D, Sanson A: The long-term significance of teacher-rated hyperactivity and reading ability in childhood: findings from two longitudinal studies. J Child Psychol Psychiatry 2002, 43:1004-1017.

73. Noseworthy MD, Bray TM: Zinc deficiency exacerbates loss in blood-brain barrier integrity induced by hyperoxia measured by dynamic MRI. Proc Soc Exp Biol Med 2000, 223:175-182.

74. Molteni R, Barnard R, Ying Z, Roberts K, Gomez-Pinilla F: A high-fat, refined sugar diet reduces hippocampal brain-derived neurotrophic factor, neuronal plasticity, and learning. Neuroscience 2002, I I 2(4):803-8I4.

75. Hashimoto K, Iwata $Y$, Nakamura K, Tsujii M, Tsuchiya KJ, Sekine $Y$, Suzuki K, Minabe Y, Takei N, lyo M, Mori N: Reduced serum levels of brain-derived neurotrophic factor in adult male patients with autism. Prog Neuropsychopharmacol Biol Psychiatry 2006, 30(8): $1529-153 \mid$.

76. Shim SH, Hwangbo Y, Kwon YJ, Jeong HY, Lee BH, Lee HJ, Kim YK: Increased levels of plasma brain-derived neurotrophic factor in children with attention deficit-hyperactivity disorder (ADHD). Prog Neuropsychopharmacol Biol Psychiatry 2008, 32(8): 1824-1828.

77. Kidd PM: Autism, an extreme challenge to integrative medicine. Part I:the knowledge base. Altern Med Rev 2002, 7(4):292-316.

78. James SJ, Melnyk S, Jernigan S: Low plasma methionine, cysteine, and glutathione levels are associated with increased frequency of common polymorphisms affecting methylation and glutathione pathways in children with autism. Experimental Biology Conference: 2 April 2005; San Diego 2005.
79. Reed $\mathrm{D}$, Orrenius $\mathrm{S}$ : The role of methionine in glutathione biosynthesis by isolated rat hepatocytes. Biochem Biophys Res Commun 1997, 77: 1257-I 264 .

80. James SJ, Cutler P, Melnyk S, Jernigan S, Janak L, Gaylor DW, Neubrander JA: Metabolic biomarkers of increased oxidative stress and impaired methylation capacity in children with autism. Am / Clin Nutr 2004, 80(6): 16 I I-16I7.

81. Almaguer-Melian W, Cruz-Aguado R, Bergado JA: Synaptic plasticity is impaired in rats with a low glutathione content. Synapse 2000, 38:369-374.

82. White AR, Cappai R: Neurotoxicity from glutathione depletion is dependent on extracellular trace copper. I Neurosci Res 2003, 7 I:889-897.

83. Rotruck JT, Pope AL, Ganther HE, Swanson AB, Hafeman DG, Hoekstra WG: Selenium: biochemical role as a component of glutathione peroxidase. Science 1973, 179:588-590.

84. Sparaco M, Gaeta LM, Tozzi G, Bertini E, Pastore A, Simonati A, Santocelli FM, Piemonte F: Protein glutathionylation in human central nervous system: potential role in redox regulation of neuronal defense against free radicals. J Neurosci Res 2006, 83(2):256-263.

85. Patrick L: Selenium biochemistry and cancer: a review of the literature. Altern Med Rev 2004, 9(3):239-258.

86. Shanker G, Aschner JL, Syversen T, Aschner M: Free radical formation in cerebral cortical astrocytes in culture induced by methylmercury. Brain Res Mol Brain Res 2004, I 28(I):48-57.

87. Makani S, Gollapudi S, Yel L, Chiplunkar S, Gupta S: Biochemical and molecular basis of thiomersal-induced apoptosis in $t$ cells: a major role of mitochondrial pathway. Genes Immun 2002, 3:270-278.

88. Dringen R: Metabolism and functions of glutathione in brain. Prog Neurobiol 2000, 62:649-67I.

89. Sitta A, Barschak AG, Deon M, Barden AT, Biancini GB, Vargas PR, de Souza CF, Netto C, Wajner M, Vargas CR: Effect of short- and long-term exposition to high phenylalanine blood levels on oxidative damage in phenylketonuric patients. Int J Dev Neurosci 2009, 27(3):243-247.

90. Brkljacic J, Milutinovic DV, Dundjerski J, Matic G: Mercury stimulates rat liver glucocorticoid receptor association with Hsp90 and Hsp70. J Biochem Mol Toxicol 2004, I 8(5):257-260.

91. De Moor JM, Kennette WA, Collins OM, Koropatnick J: Zinc-metallothionein levels are correlated with enhanced glucocorticoid responsiveness in mouse cells exposed to $\mathrm{ZnCl}_{2}, \mathrm{HgCl}_{2}$, and heat shock. Toxicol Sci 200I, 64:67-76.

92. Macho A, Hirsch T, Marzo I, Marchetti P, Dallaporta B, Susin SA, Zamzami N, Kroemer G: Glutathione depletion is an early and calcium elevation is a late event of thymocyte apoptosis. J Immunol 1997, I58(10):46|2-4619.

93. Patel R, Mclntosh L, McLaughlin J, Brooke S, Nimon V, Sapolsky R: Disruptive effects of glucocorticoids on glutathione peroxidase biochemistry in hippocampal cultures. J Neurochem 2002, 82: $118-125$

94. Coyle P, Philcox JC, Carey LC, Rofe AM: Metallothionein: the multipurpose protein. Cell Mol Life Sci 2002, 59:627-647.

95. Fraker PJ, King LE, Laakko T, Vollmer TL: The dynamic link between the integrity of the immune system and zinc status. J Nutr 2000:1399S-1406S.

96. Palmiter RD: The elusive function of metallothioneines. Proc Natl Acad Sci 1998, 95:8428-8430.

97. Simpkins CO: Metallothionein in human disease. Cell Mol Biol (Noisy-le-grand) 2000, 46(2):465-488.

98. Johnson S: The possible role of gradual accumulation of copper, cadmium, lead, and iron depletion of zinc, magnesium, selenium, vitamins B2, B6, D, and E and essential fatty acids in multiple sclerosis. Med Hypotheses 2000, 55(3):239-24I.

99. Klaassen CD, Liu J: Metallothionein transgenic and knock-out mouse models in the study of cadmium toxicity. J Toxicol $\mathrm{Sci}$ 1998, 23:97-102.

100. Park JD, Liu Y, Klaassen CD: Protective effect of metallothionein against the toxicity of cadmium and other metals. Toxicology 2001, 163(2-3):93-100.

10I. Shimada A, Nagayama Y, Morita T, Yoshida M, Suzuki JS, Satoh M, Tohyama C: Localization and role of metallothioneins in the olfactory pathway after exposure to mercury vapor. Exp Toxicol Pathol 2005, 57(2): I I7-I 25. 
102. Syring RA, Hoexum Brouwer T, Bouwer M: Cloning and sequencing of cDNAs encoding for a novel copper-specific metallothionein and two cadmium-inducible metallothioneins from the blue-crab Callinectes sapidus. Comp Biochem Physiol C Toxicol Pharmacol 2000, I 25(3):325-332.

103. Choudhuri S, Kramer KK, Berman NE, Dalton TP, Andrews GK, Klaassen CD: Constitutive expression of metallothionein gene in mouse brain. Toxicol Appl Pharmacol 1995, I 3 I(1): 144-154.

104. Chuah MI, Getchell ML: Metallothionein in olfactory mucosa of Alzheimer's disease patients and apoE-deficient mice. Neuroreport 1999, I0(9): 1919-1924.

105. Yu WH, Lukiw W], Bergeron C, Niznik HB, Fraser PE: Metallothionein III is reduced in Alzheimer's disease. Brain Res 200 I, 894(I):37-45.

106. Achner $M$ : The functional significance of brain metallothioneins. FASEB J 1996, 10:11 129-1 I36.

107. Miyazaki I, Asanuma M, Higashi Y, Sogawa CA, Tanaka K, Ogawa N Age-related changes in expression of metallothionein-III in rat brain. Neurosci Res 2002, 43:323-333.

108. Shankar AH, Prasad AS: Zinc and immune function: the biological basis of altered resistance to infection. Am J Clin Nutr 1998, 68(suppl):447S-463S

109. Sprietsma JE: Modern diets and diseases: NO-zinc balance, under Thl, zinc and nitrogen monoxide (NO) collectively protect against viruses, AIDS, autoimmunity, diabetes, allergies, asthma, infectious diseases, atherosclerosis and cancer. Med Hypotheses 1999, 53(1):6-16.

110. Wainwright PE: Dietary essential fatty acids and brain function: a developmental perspective on mechanisms. Proc Nutr Soc 2002, $6 I(I): 6 I-69$.

III. Hallahan B, Garland MR: Essential fatty acids and their role in the treatment of impulsivity disorders. Prostaglandins Leuko Essent Fatty Acids 2004:21 I-216.

112. Richardson A: The importance of omega 3 fatty acids for behaviour, cognition and mood. Scand J Food Nutri 2003, 47(2):92-98

I 13. Ottoboni F, Ottoboni A: Can attention deficit-hyperactivity disorder result from nutritional deficiency? J Am Physicians Surg 2003, 8(2):58-60.

II4. Food and Drug Administration [http://www.fda.gov/Food/Food IngredientsPackaging/GenerallyRecognizedasSafeGRAS/ GRASListings/ucm I54/26.htm]

115. Lukiw W], Bazan NG: Docosahexaenoic acid and the aging brain. J Nutr 2008, I 38( I 2):25 I0-25I4.

116. Lukiw W]: Docosahexaenoic acid and amyloid-beta peptide signaling in Alzheimer's disease. World Rev Nutr Diet 2009, 99:55-70.

I 17. Wu A, Ying Z, Gomez-Pinilla F: Dietary omega-3 fatty acids normalize bdnf levels, reduce oxidative damage, and counteract learning disability after traumatic brain injury in rats. J Neurotrauma 2004, 2 I ( I 0): I457-I 467.

I 18. Lukiw WJ, Cui JG, Marcheselli VL, Bodker M, Botkjaer A, Gotlinger $K$, Serhan CN, Bazan NG: A role for docosahexaenoic acidderived neuroprotectin $D I$ in neural cell survival and Alzheimer disease. J Clin Invest 2005, I I 5( I 0):2774-2783.

119. Stevens LJ, Zentall SS, Deck JL, Abate ML, Watkins BA, Lipp SR, Burgess JR: Essential fatty acid metabolism in boys with attention-deficit hyperactivity disorder. I Clin Nutr 1995 62(4):76I-768.

120. Mitchell EA, Aman MG, Turbott SH, Manku M: Clinical characteristics and serum essential fatty acid levels in hyperactive children. Clin Pediatr (Phila) 1987, 26(8):406-4II.

121. Colter AL, Cutler C, Meckling KA: Fatty acid status and behavioural symptoms of attention deficit hyperactivity disorder in adolescents: a case control study. Nutr J 2008, I4(78 [http:// www.nutritionj.com/content/pdf//475-289|-7-8.pdf].

122. Voigt RG, Llorente AM, Jensen CL, Fraley JK, Berretta MC, Heird WC: A randomized double-blind, placebo-controlled trial of docosahexaenoic acid supplementation in children with attention-deficit/hyperactivity disorder. I Pediatr 200I, 139(2): 189-196.

123. Hirayama S, Hamazaki T, Terasawa K: Effect of docosahexaenoic acid-containing food administration on symptoms of attention-deficit/hyperactivity disorder-a placebo-controlled double blind study. Eur ] Clin Nutr 2003, 58:467-473.
124. Richardson AJ, Montgomery P: The Oxford-Durham study: a randomized, controlled trial of dietary supplementation with fatty acids in children with developmental coordination disorder. Pediatrics 2005, I/ 5(5): /360-1366.

125. Sorgi PJ, Hallowell EM, Hutchins HL, Sears B: Effects of an openlabel pilot study with high-dose EPA/DHA concentrates on plasma phospholipids and behavior in children with attention deficit hyperactivity disorder. Nutr J 2007, 13(616 [http:// www.nutritionj.com/content/pdf/|475-289|-6-|6.pdf].

126. Sinn N, Bryan J: Effect of supplementation with polyunsaturated fatty acids and micronutrients on learning and behavior problems associated with child ADHD. J Dev Behav Pediatr 2007, 28(2):82-9|

127. Johnson M, Ostlund S, Fransson G, Kadesjo B, Gillberg C: Omega-3/ omega- 6 fatty acids for attention deficit hyperactivity disorder: a randomized placebo-controlled trial in children and adolescents. J Atten Disord 2009, I 2(5):394-40I.

128. Belanger SA, Vanasse M, Spahis S, Sylvestre MP, Lippe S, L'Heureux F, Ghadirian P, Vanasse CM, Levy E: Omega-3 fatty acid treatment of children with attention-deficit hyperactivity disorder: a randomized, double-blind, placebo-controlled study. Paediatr Child Health 2009, I 4(2):89-98.

129. Peet M: Eicosapentaenoic acid in the treatment of schizophrenia and depression: rationale and preliminary doubleblind clinical trial results. Prostaglandins Leukot Essent Fatty Acids 2003, 69:477-485.

130. Richardson AJ: Fatty acids in dyslexia, dyspraxia, ADHD and autistic spectrum. Nutri Prac 200I, 3(3): 18-24.

13I. Arnold LE: Treatment alternatives for Attention-Deficit/ Hyperactivity Disorder (ADHD). J Atten Disord 1999, 3(I):30-48.

132. Burgess JR, Stevens L, Zhang W, Peck L: Long-chain polyunsaturated fatty acids in children with attention-deficit hyperactivity disorder. Am J Clin Nutr 2000, $71: 327 \mathrm{~S}-330 \mathrm{~S}$.

133. Kozielec T, Starobrat-Hermelin B: Assessment of magnesium levels in children with attention deficit hyperactivity disorder (ADHD). Magnes Res 1997, I0(2): |43-|48.

134. Starobrat-Hermelin B, Kozielec $T$ : The effects of magnesium physiological supplementation on hyperactivity in children with attention deficit hyperactivity disorder (ADHD): postive response to magnesium oral loading test. Magnes Res 1997, 10(2): 149-156.

135. Galland L: Impaired essential fatty acid metabolism in latent tetany. Magnesium 1985, 4:333-338.

136. Mahfouz MM, Smith TL, Kummerow FA: Changes in linoleic acid metabolism and cellular phospholipid fatty acid composition in LLC-PK cells cultured at low magnesium concentrations. Biochim Biophys Acta 1989, 1006(I):70-74.

137. Arnold LE, DiSilvestro RA: Zinc in attention-deficit/hyperactivity disorder. J Child Adolesc Psychopharmacol 2005, I 5(4):619-627.

138. Bilici M, Yildirim F, Kandil S, Bekaroglu M, Yildirmis S, Deger O, Ulgen $M$, Yildiran A, Aksu H: Double-blind placebo-controlled study of zinc sulfate in the treatment of attention deficit hyperactivity disorder. Prog Neuropsychopharmacol Biol Psychiatry 2004, 28(1): $181-190$

139. Guallar E, Sanz-Gallardo MI, Van't Veer P, Bode P, Aro A, GomezAracena J, Kark JD, Riemersma RA, Martin-Moreno JM, Kok FJ, Heavy Metals and Myocardial Infarction Study Group: Mercury, fish oils, and the risk of myocardial infarction. N Engl J Med 2002, 347(22): 1747- 1754 .

140. Innis SM, Palaty J, Vaghri Z, Lockitch G: Increased levels of mercury associated with high fish intakes among children from Vancouver, Canada. J Pediatr 2006, I48(6):759-63.

141. United Kingdom Food Standards Agency [http:// www.food.gov.uk/multimedia/pdfs/fsis8005.pdf]

142. World Health Organization Joint Expert Committee on Food Additives [http://whqlibdoc.who.int/trs/ WHO TRS 928.pdf]

143. United States Code of Federal Regulations [http://ecfr.gpoac cess.gov/cgi/t/text/textidx?c=ecfr\&sid=1070b 19 eb50e 562 daa $872 \mathrm{cfa} \mid 755 \mathrm{aa} 09 \mathrm{\& rgn}=$ div $5 \&$ vie $w=$ text\&node $=21: 1.0 .1$. I.27\&idno $=2$ I $\# 21$ : I.0.1.I.27.I.3I.9]

144. United Kingdom Food Standards Agency [http:www.food.gov.uk/safereating/chemsafe/additivesbranch/colours/col ourfree/] 
145. Hughes JR: A review of recent reports on autism: 1000 studies published in 2007. Epilepsy Behav 2008, 13(3):425-437.

146. Shahar E: Causal diagrams for encoding and evaluation of information bias. J Eval Clin Prac 2009, I 5(3):436-440.

147. Curtis LT, Patel K: Nutritional and environmental approaches to preventing and treating autism and attention deficit hyperactivity disorder (ADHD): a review. J Altern Complement Med 2008, I 4(1):79-85.

Publish with Bio Med Central and every scientist can read your work free of charge

"BioMed Central will be the most significant development for disseminating the results of biomedical research in our lifetime. " Sir Paul Nurse, Cancer Research UK

Your research papers will be:

- available free of charge to the entire biomedical community

- peer reviewed and published immediately upon acceptance

- cited in PubMed and archived on PubMed Central

- yours - you keep the copyright

Submit your manuscript here:

http://www.biomedcentral.com/info/publishing_adv.asp
BioMedcentral 